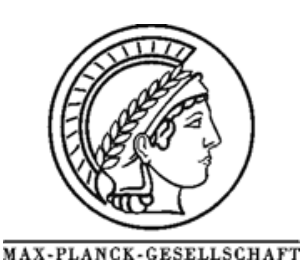

\title{
In situ-XAS and catalytic study of acrolein hydrogenation over silver catalyst: Control of intramolecular selectivity by the pressure
}

\author{
M. Bron ${ }^{\dagger}$, D. Teschner ${ }^{\ddagger}$, A. Knop-Gericke ${ }^{\ddagger}$, A. Scheybal ${ }^{\ddagger}$, Berndt Steinhauer $^{\ddagger}$, M. Hävecker ${ }^{\ddagger}$, \\ R. Födisch ${ }^{\S}$, D. Hönicke ${ }^{\S}$, R. Schlögl ${ }^{\ddagger}$, P. Claus ${ }^{\dagger} *$ \\ ${ }^{\dagger}$ Department of Chemistry, Darmstadt University of Technology, Petersenstr. 20, D-64287 Darmstadt, Germany \\ ${ }^{\ddagger}$ Department of Inorganic Chemistry, Fritz-Haber-Institute of the MPG, Faradayweg 4-6, 14195 Berlin, Germany \\ ${ }^{\S}$ Chemnitz University of Technology, Str. d. Nationen 62, D-09111 Chemnitz, Germany
}

* Corresponding author: e-mail claus@ct.chemie.tu-darmstadt.de, phone +49-6151-165369, fax +49-6151-164788

Received: 15 October 2005

\begin{abstract}
The gas phase hydrogenation of acrolein over $7.5 \% \mathrm{Ag} / \mathrm{SiO}_{2}$ has been studied in a broad pressure range from 7.5 mbar to 20 bar. Higher pressures favour the formation of allyl alcohol (selectivities up to $42 \%$ ), whereas at low pressures propionaldehyde is by far the main product. In situ-XAS has been performed at 7.5 mbar in order to gain insight into the interaction of acrolein with $\mathrm{Ag}(111)$. Hydrogenated propionaldehyde-like surface species could be detected which orientated parallel to the surface. The observed intermediate correlates perfectly with the online catalytic data.
\end{abstract}

\section{Introduction}

One feasible way to produce unsaturated alcohols, a desired group of intermediates of fine chemical processes, is the selective hydrogenation of unsaturated aldehydes [1]. However, when using lower $\alpha, \beta$-unsaturated aldehydes, like acrolein and crotonaldehyde, and conventional hydrogenation catalysts like $\mathrm{Pt}, \mathrm{Ni}$ or $\mathrm{Ru}$ on $\mathrm{SiO}_{2}$ or $\mathrm{Al}_{2} \mathrm{O}_{3}$, the observed selectivities to unsaturated alcohols are not attractive for industrial applications. Acrolein, for example, can either be hydrogenated to the saturated aldehyde, propionaldehyde (PA), or to the unsaturated alcohol, allyl alcohol $(\mathrm{AyOH})$. From both products, the consecutive hydrogenation to n-propanol is possible. Using Ru- and Ni catalysts, the selectivity to the unsaturated alcohol is low [1]. Gold and silver catalysts, on the other hand, show much higher intrinsic selectivities to the desired allylic alcohols [ $\left.{ }^{2}-6\right]$. In case of acrolein hydrogenation, the selectivity to propanol or by-products is low (in most cases below $5 \%$ ), and mainly allyl alcohol and propionaldehyde are formed via hydrogenation of the $\mathrm{C}=\mathrm{O}$ group and $\mathrm{C}=\mathrm{C}$ bond, respectively. We therefore turned our focus on the investigation of acrolein hydrogenation over silver (and gold) catalysts.

Many important features in catalysis like adsorption/desorption, orientation of adsorbates, solubility of reactants in the active phase etc. and even the reaction mechanism may exhibit strong pressure dependence and may influence the product distribution in heterogeneously catalyzed reactions. Due to the absence of consecutive reactions, the reaction network of acrolein hydrogenation is very simple (indeed, the reaction can be treated as simple parallel reaction) and perfectly suited to study the effect of reaction pressure on the intramolecular selectivity. We have therefore studied acrolein hydrogenation in a broad pressure range to evaluate the influence of pressure on the product distribution. Additionally, in situ-X-ray absorption spectroscopy has been applied for the first time to gain information about the chemisorption modus of acrolein or possible reaction intermediates.

\section{Experimental}

Catalytic experiments using $\mathrm{Ag} / \mathrm{SiO}_{2}$ catalyst have been performed in the pressure region of 7.5 mbar to 20 bar. In the range of 350 mbar to $20 \mathrm{bar}$, experiments have been performed in two different continuous gas flow reaction systems (one for the region of 350-950 mbar and another one for 5 to 20 bar $\left[{ }^{7}\right]$ ) with a gas chromatograph as analytical system. The catalyst $\left(7.5 \% \mathrm{Ag} / \mathrm{SiO}_{2}-\mathrm{IW}\right)$ has 
been prepared by an incipient wetness technique using Ag lactate as precursor. After impregnation, the catalyst has been dried and reduced at $325{ }^{\circ} \mathrm{C}$. The real metal content was $7.5 \%$ [6]. Additionally, the catalysts have been reduced in situ at $250{ }^{\circ} \mathrm{C}$ before each experiment in pure hydrogen. Mass flow controllers have been used for gas feeding; acrolein has been dosed by a liquid flow controller and evaporated afterwards. The reaction temperature was 250 ${ }^{\circ} \mathrm{C}$. $\mathrm{H}_{2}$ /acrolein ratio was 20:1 with a $\mathrm{H}_{2}$ flow rate of 6.7 $\mathrm{l} / \mathrm{h}$. W/F $/ \mathrm{F}_{\text {acrolein }}$ (weight of catalyse per feed of acrolein) was varied between 2 and 15 in order to determine selectivities at similar conversions.

Additionally, catalytic experiments have been performed at 7.5 mbar during in situ-XAS measurements (see below).

XAS (X-ray absorption spectroscopy) experiments were performed in a special reactor cell at the undulator beamline U/49-2 at BESSY in Berlin, Germany. Details about the set-up and the data processing can be found in the literature [8, 9]. Carbon K-edge gas phase and collector plate (surface related plus gas phase) signal were recorded in the total electron yield mode (TEY) in situ. The reactor cell was operated in batch mode with a gas mixture of 0.01 mbar acrolein, 0.01 mbar argon and $7.48 \mathrm{mbar}^{\mathrm{H}_{2}}$. The reaction was monitored by online mass spectrometer (MS). In situ-XAS measurements were carried out on Ag(111) single-crystal and on $\mathrm{Ag} / \mathrm{SiO}_{2}$. The angle of incident beam to sample surface was varied on the single crystal $\left(90^{\circ}\right.$ : normal incidence, $30^{\circ}$ : grazing incidence).

\section{Results and Discussion}

\section{Catalysis}

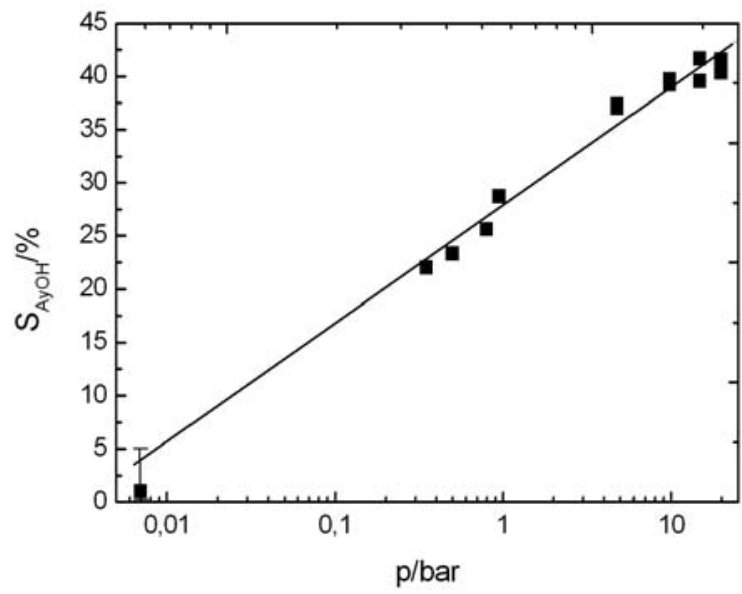

Figure 1: Pressure dependence of the selectivity to allyl alcohol in the gas phase hydrogenation of acrolein over $7.5 \% \mathrm{Ag} / \mathrm{SiO} 2-\mathrm{iw}$. Reaction temperature $250^{\circ} \mathrm{C}$.

Our previous report [6] indicated a pressure dependent product distribution in the 5-20 bar pressure region important to industry. In recent experiments, a strong de- pendence of the selectivity to allyl alcohol on the reaction pressure in hydrogenation of acrolein over silver catalysts has been found in a pressure range from 20 bar down to 7.5 mbar, which is displayed in Fig. 1 for the silica supported silver catalyst. The values of Fig. 1 have been obtained from the three different set-ups. A more detailed investigation of the pressure dependence has revealed that, at least for the high-pressure range (5...20 bar), the selectivities depend on both the partial pressure of acrolein and hydrogen, but not on the total reaction pressure [6].

\section{In-situ XAS}

Ag(111) single crystal was employed to learn about the orientation of acrolein on well-oriented surfaces. Soft $\mathrm{X}$-ray excited absorption spectroscopy has been used in situ $[8,9]$ in the presence of acrolein/hydrogen gas mixture (0.01 mbar acrolein, 0.01 mbar argon and $7.48 \mathrm{mbar}_{2}$ ). The catalytic activity was monitored online, and the reaction proceeds exclusively towards propionaldehyde formation as was observed with the supported silver sample. Unexpectedly, the silver samples showed catalytic activity during the in situ-XAS experiments, measurable with MS, even at room temperature. Additionally, decarbonylation of acrolein has been observed at higher temperatures. This points to a beam induced effect on the illuminated surface.

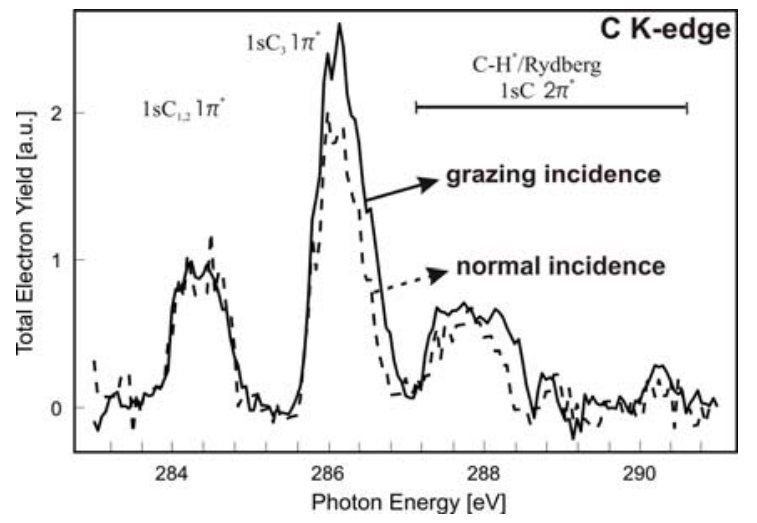

Figure 2: Carbon K-edge spectra of acrolein/ $\mathrm{H}_{2}$ mixture on $\mathrm{Ag}(111)$. Shown is a part of the collector plate spectra (surface related plus gas-phase signal) at two incidence angle (normal: $90^{\circ}$; grazing: $30^{\circ}$ ) after background subtraction.

Fig. 2 shows the C K-shell collector plate (gas phase plus surface related signal) spectra of acrolein on $\mathrm{Ag}(111)$ recorded at grazing (E vector $30^{\circ}$ from surface normal) and normal X-ray incidence ( $\mathrm{E}$ vector in the surface plane) recorded at room temperature. A quasi-continuous background subtraction has been used to allow a good comparison of the resonant features. The spectra are dominated by the gas phase contribution, which should be obviously angular independent. Moreover, at normal incidence the gas phase and the collector plate spectra were almost equal. At grazing incidence the intensity of the $1 \mathrm{sC}_{3} 1 \pi^{*}$ transition and those in the third peak (except at about $287.7 \mathrm{eV}$ ) are 


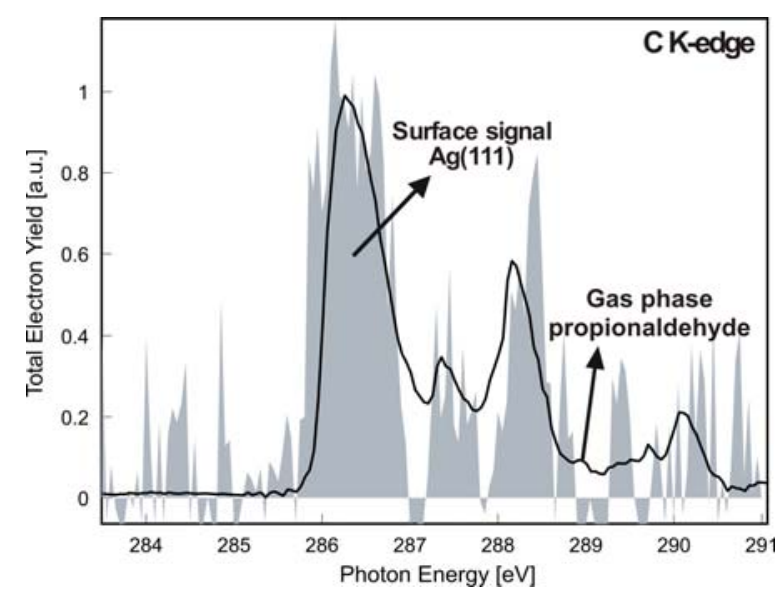

Figure 3: Difference spectrum of grazing - normal incidence spectrum taken from Fig. 2 (shown here as shaded area). As a comparison gas-phase spectrum of propionaldehyde is shown after background subtraction.

enhanced, if the spectra are normalized at the first, $1 \mathrm{sC}_{1,2}$ $1 \pi^{*}$ transition. (According to the "building block" model, the $\pi^{*}$ transitions correspond to the excitation from the $1 \mathrm{~s}$ core shell to the first $\pi^{*}$ antibonding orbital, respectively to the first/second $(\mathrm{C}=\mathrm{C})$ or to the third $(\mathrm{C}=\mathrm{O})$ carbon atom.) However, there is no difference between the corresponding gas phase spectra while measured at two different angles of incidence, thus the conversion between the two scans was lower than detectable by XAS. As a result of the dipole selection rule, the resonance intensity corresponding to a molecular orbital final state is larger if the $\mathrm{E}$ vector points in the direction of that molecular orbital. Therefore the enhanced intensity points to orbitals perpendicular to the surface. Thus the axes of $\pi$-like functional groups $(\mathrm{C}=\mathrm{O})$ lie parallel to the surface (the $\pi$ orbital itself is perpendicular) and $\sigma^{*}$ orbitals $(\mathrm{C}-\mathrm{H})$ orientate rather perpendicular. Consequently, the surface species is in the lying-down orientation in this low-pressure region (7.5 mbar). Subtracting the normal incidence spectrum of $\mathrm{Ag}(111)$ from the grazing incidence spectrum leads to the rather noisy signal shown in Fig. 3. This signal is now completely surface related and orientation enhanced by the selection rule. Although the quality of the spectrum is rather poor, the similarity to the gas-phase propionaldehyde signal (after similar background subtraction) is striking. Consequently, the surface signal measured on $\mathrm{Ag}(111)$ during acrolein hydrogenation consist mainly of a propionaldehyde-like surface entity orientated in the "lying-down" manner to the surface. This species can be considered as a partly hydrogenated acrolein that after further hydrogen addition desorbs as propionaldehyde.

We have shown above, that at low pressures propionaldehyde is preferentially formed. Parallel to this, at the silver surface flat lying propionaldehyde-like intermediate was observed, thus the spectroscopic surface information correlates perfectly with the catalytic observations. To minimize propionaldehyde formation one has to avoid that acrolein adsorbed in a flat-lying manner on densely packed silver crystal planes. This can be done apparently in a cetain level by increasing the partial pressure of the reactants forcing acrolein to a higher coverage, which most probably modifies the adsorption geometry on the catalyst surface. Another possibility is to create defect rich Ag surface where acrolein can preferentially interact with the surface through the carbonyl group [10], increasing therefore the probability of $\mathrm{C}=\mathrm{O}$ hydrogenation. To the best of our knowledge, no other studies exist in the pressure gap using silver catalysts for hydrogenation. However, for the case of acrolein adsorption on $\mathrm{Pt}(111)$, it has been shown by DFT calculations and HR-EELS that the structure of surface species is coverage dependent changing from a flat coordination at low coverage towards a high coverage $\eta_{2^{-}}$ cis and $\eta_{2}$-trans form on the surface, thus changing the selectivity in hydrogenation $\left[{ }^{11}\right]$.

\section{Acknowledgements}

This research is funded by the DFG (German research foundation) within the priority program 1091 "Bridges between real and ideal systems in heterogeneous catalysis". The reliance and tolerance of BESSY people carrying out measurements at BESSY with acrolein is gratefully acknowledged.

\section{References}

[1] P. Claus, Top. Catal. 5 (1998) 51.

[2] P. Claus, H. Hofmeister, J. Phys. Chem. B 103 (1999) 2766.

[3] P. Claus, A. Brückner, C. Mohr, H. Hofmeister, J. Am. Chem. Soc. 122 (2000) 11430.

[4] C. Mohr, H. Hofmeister, P. Claus, J. Catal. 213 (2003) 86.

[5] C. Mohr, H. Hofmeister, J. Radnik, P. Claus, J. Am. Chem. Soc. 125 (2003),1905.

[6] M. Bron, E. Kondratenko, A. Trunschke, P. Claus, Z. Phys. Chem. 218 (2004) 405.

[7] M. Lucas, P. Claus, Chem.-Ing.-Techn. 67 (1995) 773.

[8] A. Knop-Gericke, M. Hävecker, T. Neisius, T. SchedelNiedrig, Nucl. Instrum.

[9] Method A 406 (1998) 311.

[10] A. Knop-Gericke, M. Hävecker, T. Schedel-Niedrig, R. Schlögl, Catal. Lett. 66 (2000) 215.

[11] S. Fuji, N. Osaka, M. Akita, K. Itoh, J. Phys. Chem. 99 (1995) 6994.

[12] D. Loffreda, Y. Jugnet, F. Delbecq, J.C. Bertolini, P. Sautet, J. Phys. Chem. B $108 \quad$ (2004) 9085. 